\title{
The Superior Temporal Sulcus Is Causally Connected to the Amygdala: A Combined TBS-fMRI Study
}

\author{
David Pitcher, ${ }^{1}$ Shruti Japee, ${ }^{2}$ Lionel Rauth, ${ }^{2}$ and ${ }^{\circ}$ Leslie G. Ungerleider ${ }^{2}$ \\ ${ }^{1}$ Department of Psychology, University of York, Heslington, York, Y0105DD, United Kingdom, and ${ }^{2}$ Section on Neurocircuitry, Laboratory of Brain and \\ Cognition, National Institute of Mental Health, Bethesda, Maryland 20892
}

\begin{abstract}
Nonhuman primate neuroanatomical studies have identified a cortical pathway from the superior temporal sulcus (STS) projecting into dorsal subregions of the amygdala, but whether this same pathway exists in humans is unknown. Here, we addressed this question by combining theta burst transcranial magnetic stimulation (TBS) with fMRI to test the prediction that the STS and amygdala are functionally connected during face perception. Human participants $(N=17)$ were scanned, over two sessions, while viewing $3 \mathrm{~s}$ video clips of moving faces, bodies, and objects. During these sessions, TBS was delivered over the face-selective right posterior STS (rpSTS) or over the vertex control site. A region-of-interest analysis revealed results consistent with our hypothesis. Namely, TBS delivered over the rpSTS reduced the neural response to faces (but not to bodies or objects) in the rpSTS, right anterior STS (raSTS), and right amygdala, compared with TBS delivered over the vertex. By contrast, TBS delivered over the rpSTS did not significantly reduce the neural response to faces in the right fusiform face area or right occipital face area. This pattern of results is consistent with the existence of a cortico-amygdala pathway in humans for processing face information projecting from the rpSTS, via the raSTS, into the amygdala. This conclusion is consistent with nonhuman primate neuroanatomy and with existing face perception models.
\end{abstract}

Key words: amygdala; face perception; face processing; STS; TMS

Significance Statement

Neuroimaging studies have identified multiple face-selective regions in the brain, but the functional connections between these regions are unknown. In the present study, participants were scanned with fMRI while viewing movie clips of faces, bodies, and objects before and after transient disruption of the face-selective right posterior superior temporal sulcus (rpSTS). Results showed that TBS disruption reduced the neural response to faces, but not to bodies or objects, in the rpSTS, right anterior STS (raSTS), and right amygdala. These results are consistent with the existence of a cortico-amygdala pathway in humans for processing face information projecting from the rpSTS, via the raSTS, into the amygdala. This conclusion is consistent with nonhuman primate neuroanatomy and with existing face perception models.

\section{Introduction}

Faces provide a constantly changing source of information about other people's moods, intentions, and the focus of their attention. In humans, a face-selective region in the posterior superior temporal sulcus (pSTS) is believed to be a cortical locus for processing the dynamic aspects of faces, such as facial expression and eye

Received Jan. 11, 2016; revised 0ct. 17, 2016; accepted Nov. 16, 2016.

Author contributions: D.P. and L.G.U. designed research; D.P. and L.R. performed research; D.P. and S.J. analyzed data; D.P., S.J., and L.G.U. wrote the paper.

This work was supported by the National Institute of Mental Health Intramural Research Program. We thank Geena lanni and Kelsey Holiday for help with data collection; and Nancy Kanwisher for providing experimental stimuli.

The authors declare no competing financial interests.

Correspondence should be addressed to Dr. David Pitcher, Department of Psychology, University of York, Heslington, York, Y0105DD, United Kingdom. E-mail: david.pitcher@york.ac.uk.

DOI:10.1523/JNEUROSCI.0114-16.2016

Copyright $\odot 2017$ the authors $\quad 0270-6474 / 17 / 371156-06 \$ 15.00 / 0$ gaze (Puce et al., 1998; Allison et al., 2000; Hoffman and Haxby, 2000; Pitcher et al., 2011b; Pitcher, 2014), but the connections of the pSTS with other brain areas are unknown. One possibility, suggested by nonhuman primate neuroanatomical studies, is that faces are processed via a cortical pathway projecting from the banks of the STS to dorsal subregions of the amygdala (Aggleton et al., 1980; Stefanacci and Amaral, 2000, 2002).

Like the pSTS, the amygdala has been strongly implicated in neuroimaging studies of facial expression recognition (Morris et al., 1996; Whalen et al., 1998; Hoffman et al., 2007). In addition, lesion studies in humans and in macaques, have shown that damage to the amygdala impairs facial expression recognition (Adolphs et al., 1994, 1999; Calder et al., 1996; Hadj-Bouziane et al., 2012). Based on this evidence, a functional connection between the pSTS and amygdala has been proposed in face processing models (Haxby et al., 2000; Calder and Young, 2005). More recent neuroimaging studies (Calder et al., 2007; Pinsk et al., 2009; 


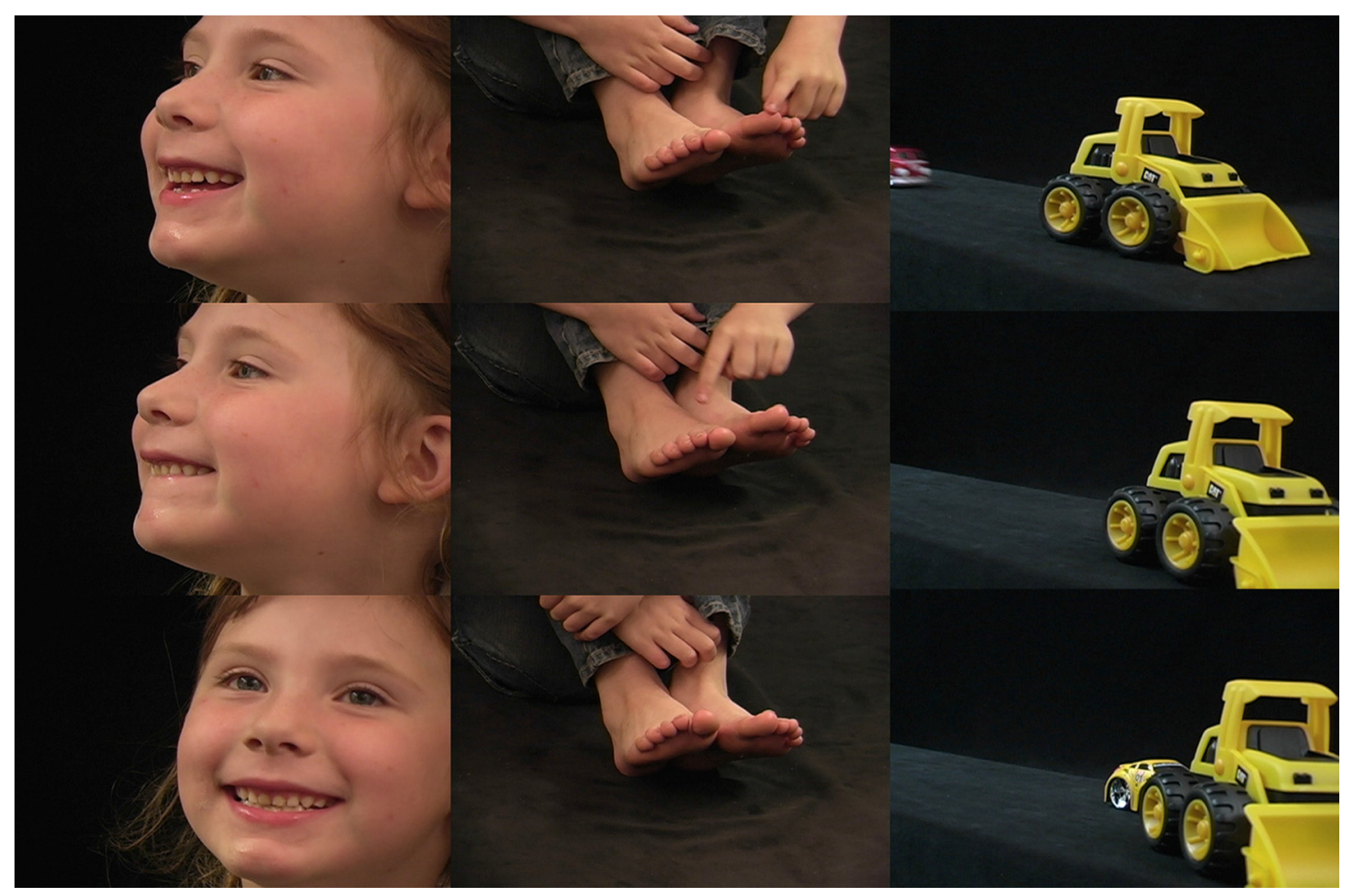

Figure 1. Static images taken from three example videos of the dynamic face, body, and object video clips.

Pitcher et al., 2011a) have identified an additional face-selective region in the right anterior STS (raSTS), further suggesting the existence of a cortical pathway projecting down the STS into the amygdala specialized for face perception. In the present study, we directly tested this proposal using a virtual lesion approach (Pitcher et al., 2014). fMRI was combined with thetaburst transcranial magnetic stimulation (TBS) to establish whether the rpSTS is causally connected to the amygdala when viewing video clips of faces.

Neurologically healthy participants completed two fMRI sessions, performed on separate days, while viewing $3 \mathrm{~s}$ videos of moving faces, bodies, and objects (Pitcher et al., 2011a). Scanning was performed before and after TBS (Huang et al., 2005) was delivered over the functionally localized right pSTS (rpSTS) or the vertex, a point on the top of the head that acted as a TBS control site. We then measured what effect TBS disruption had on the neural responses evoked in the rpSTS and in the amygdala, as well as in other face-selective regions, including the raSTS, right fusiform face area (rFFA) (Kanwisher et al., 1997; McCarthy et al., 1997) and right occipital face area (rOFA) (Gauthier et al., 2000). We reasoned that, if the rpSTS, raSTS, and right amygdala were components of a pathway for face processing, then transiently disrupting the rpSTS would reduce the neural activity evoked by faces in all three regions.

\section{Materials and Methods}

Participants. A total of 27 right-handed participants (15 females, 12 males) with normal or corrected-to-normal vision gave informed consent as directed by the National Institutes of Health Institutional Review Board. Four participants ( 2 females, 2 males) failed to complete both TBS/fMRI sessions and were excluded from further analysis.

Stimuli. Stimuli were $3 \mathrm{~s}$ video clips from three different categories (faces, bodies, and objects) that had been used in previous fMRI and TMS studies of face perception (Pitcher et al., 2011a, 2012, 2014). Stills taken from example videos are shown in Figure 1. There were 60 video clips for each category in which distinct exemplars appeared multiple times. Videos of faces and bodies were filmed on a black background, and framed close-up to reveal only the faces or bodies of 7 children as they danced or played with toys or with adults (who were out of frame). Fifteen different moving objects were selected that minimized any suggestion of animacy of the object itself or of a hidden actor moving the object (these included mobiles, wind-up toys, toy planes and tractors, balls rolling down sloped inclines). Stimuli were presented in categorical blocks and, within each block, stimuli were randomly selected from the entire set for that stimulus category. Hence, the same actor or object could appear within the same block.

A separate group of participants $(N=20)$ rated the emotional valence of our stimuli using a Likert scale $(1=$ least emotionally Valent, $7=$ most emotionally valent). The mean scores and SEs were as follows: faces $=$ $4.65(0.35)$, bodies $=2.85(0.32)$ and objects $=2.65(0.35)$. A repeatedmeasures ANOVA showed that faces were rated as significantly more emotionally valent than bodies $(p=0.001)$ and objects $(p=0.001)$. There was no significant difference between bodies and object $(p=0.5)$.

Procedure. Participants completed three separate fMRI sessions, each performed on a different day. The first session was an fMRI experiment designed to individually localize the TBS sites in each participant. The data collected in this initial session were used for TBS target site identification only. During the two subsequent fMRI sessions, participants were scanned before and after receiving TBS over either the rpSTS or the vertex. Stimulation site order was balanced across participants.

Combined TBS/fMRI sessions. Functional data were acquired over 12 blocked-design functional runs lasting $234 \mathrm{~s}$ each. Functional runs presented short video clips of faces, bodies, and objects in $18 \mathrm{~s}$ blocks that contained six $3 \mathrm{~s}$ video clips from that category. Participants were instructed to press a button when the subject in the stimulus was repeated in the same block (e.g., a repeat of the same actor, body, or object). The order of repeats was randomized and happened an average of once per block.

During each scanning session, participants exited the scanner to receive TBS over either the rpSTS or the vertex, dividing the session into six pre-TBS functional runs and six post-TBS functional runs. TBS over the rpSTS, and vertex was balanced across participants. TBS was performed 
in a separate room from the scanner and, once completed, participants reentered the scanner room immediately. Participants were out of the scanner for no more than $7 \mathrm{~min}$. Poststimulation scanning for all participants began within 5 min of TBS delivery.

Brain imaging and analysis. Participants were scanned on a research dedicated 3 tesla GE scanner. Whole-brain images were acquired using a 32 -channel head coil ( 36 slices, $3 \times 3 \times 3 \mathrm{~mm}, 0.6 \mathrm{~mm}$ interslice gap, $\mathrm{TR}=2 \mathrm{~s}, \mathrm{TE}=30 \mathrm{~ms}$ ). Slices were aligned with the anterior/posterior commissure. In addition, a high-resolution T1-weighted MP-RAGE anatomical scan (T1-weighted FLASH, $1 \times 1 \times 1 \mathrm{~mm}$ resolution) was acquired to anatomically localize functional activations. In each scanning session, functional data were acquired over 12 blocked-design functional runs lasting $234 \mathrm{~s}$. Six runs were collected before TBS being delivered, and six runs were collected after TBS was delivered.

fMRI data were analyzed using AFNI (http://afni.nimh.nih.gov/afni). Data from the first four TRs from each run were discarded. The remaining images were slice-time corrected and realigned to the last volume of the last run before TBS during the TBS to vertex session, and to the corresponding anatomical scan. The volume registered data were spatially smoothed with a $4 \mathrm{~mm}$ FWHM Gaussian kernel. Signal intensity was normalized to the mean signal value within each run and multiplied by 100 so that the data represented percentage signal change from the mean signal value before analysis.

A GLM was established by convolving the standard hemodynamic response function with the 3 regressors of interest (one for each stimulus category: faces, bodies, and objects). Regressors of no interest (e.g., 6 head movement parameters obtained during volume registration and AFNI's baseline estimates) were also included in this GLM.

Data from pre-TBS runs 1, 3, and 5 from the rpSTS stimulation session and pre-TBS runs 2, 4, and 6 from the vertex stimulation session, were used to identify face-selective regions of interest (ROIs). Regions that showed a greater response to dynamic faces than dynamic objects were identified as face-selective. The remaining runs (pre-TBS runs 2, 4, and 6 and post-TBS runs $1-6$ from the rpSTS stimulation session and pre-TBS runs 1,3 , and 5 and post-TBS runs 1-6 from the vertex stimulation session) were used to examine the effect of TBS stimulation within the face selective ROIs.

TBS site localization and parameters. Stimulation sites were localized using individual structural and functional images collected during an fMRI localizer task that each participant completed before the combined TBS/fMRI sessions. In the localizer session, participants viewed the same dynamic face, body, and object stimuli described above. The stimulation site targeted in the rpSTS of each participant was the peak voxel in the face-selective ROI identified using a contrast of greater activation by dynamic faces than dynamic objects. The vertex site was identified as a point on the top of the head halfway between the nasion (the tip of the nose) and the inion (the point at the back of the head). TBS sites were identified using the Brainsight TMS-MRI coregistration system (Rogue Research), and the proper coil locations were then marked on each participant's scalp using a marker pen.

A Magstim Super Rapid Stimulator (Magstim) was used to deliver the TBS via a figure-eight coil with a wing diameter of $70 \mathrm{~mm}$. TBS was delivered at an intensity of $80 \%$ of active motor threshold or $30 \%$ of machine output (whichever was higher) over each participant's functionally localized rpSTS or vertex. We used a continuous TBS paradigm (Huang et al., 2005) of 3 pulses at $50 \mathrm{~Hz}$ repeated at $200 \mathrm{~ms}$ intervals for a $60 \mathrm{~s}$ uninterrupted train of 900 pulses. This same protocol was used in a previous combined TBS/fMRI study of face perception (Pitcher et al., 2014). The Stimulator coil handle was held pointing upwardand parallel to the midline.

\section{Results}

Face-selective ROIs, including those in the amygdala, were identified individually in each participant with independent data using a contrast of fMRI responses evoked by dynamic faces greater than responses evoked by dynamic objects (using a statistical threshold of $p=0.0001$ ). We identified five core ROIs: the rpSTS, the raSTS, the rFFA, the rOFA, and the amygdala in 17 of the 23 participants. The BOLD response to the three stimulus categories (faces, bodies, and objects) was calculated in each ROI before and after TBS was delivered over the rpSTS and the vertex control site (Fig. 2). Pre-TBS stimulation data were calculated by taking three runs from each of the two pre-TBS sessions so there were six pre-TBS runs and six post runs collected in each of the post-TBS rpSTS and post-TBS vertex sessions (for more information, see Materials and Methods).

An analysis of the pre-TBS data collected during the rpSTS and vertex stimulation sessions demonstrated that there were no significant differences between the sessions. The data were entered into a 2 (TMS Session: Pre-TBS to rpSTS; Pre-TBS to vertex) $\times 3$ (Stimuli: Faces; Bodies; Objects) $\times 5$ (ROI: rpSTS; raSTS; rFFA; rOFA; Right amygdala) repeated-measures ANOVA. Crucially, there was no main effect of session $\left(F_{(1,16)}=\right.$ $0.2, p=0.70)$ as well as no interaction between session and ROI $\left(F_{(4,64)}=2.1, p=0.15\right)$, session and stimuli $\left(F_{(2,32)}=0.9, p=\right.$ $0.40)$, and no three-way interaction between session, ROI, and stimuli $\left(F_{(8,128)}=0.5, p=0.90\right)$. Because we did not find any differences in baseline activity in the two pre-TBS conditions, we combined the 3 runs from pre-TBS to rpSTS and 3 runs from pre-TBS to vertex. This was done to use the same amount of data (6 runs) for pre-TBS baseline condition as the post-TBS conditions.

To establish what effect TBS stimulation had on the BOLD responses in face-selective regions, the data were entered into a 3 (Stimulus category: Faces; Bodies; Objects) by 3 (TBS: Pre-TBS; TBS to rpSTS; TBS to vertex) $\times 5$ (ROI: rpSTS; raSTS; rFFA; rOFA; Right amygdala) repeated-measures ANOVA. Results showed significant main effects of stimulus category $\left(F_{(2,32)}=\right.$ $181, p<0.001)$ and ROI $\left(F_{(4,64)}=54, p<0.001\right)$ but not of TBS $\left(F_{(2,32)}=1.9, p=0.164\right)$. There was a significant interaction between stimulus category and ROI $\left(F_{(8,128)}=18, p<0.001\right)$ and, crucially, also between stimulus category and TBS $\left(F_{(4,64)}=\right.$ $2.5, p=0.041)$. There was no interaction between stimulus category, TBS, and ROI $\left(F_{(16,256)}=0.7, p=0.76\right)$.

Post hoc tests showed that TBS delivered over the rpSTS significantly reduced the BOLD response to faces relative to the pre-TBS baseline in the $\operatorname{rpSTS}(p=0.019)$, the raSTS $(p=$ $0.047)$, and the amygdala $(p=0.008)$ but not in the rFFA ( $p=$ $0.41)$ or the rOFA $(p=0.27)$. There were no significant effects of TBS disruption for the body $(p>0.35)$ or object $(p>0.44)$ stimulus categories in any of the ROIs.

\section{Discussion}

In the present study, we investigated the causal connections of the face-selective pSTS using a combination of TBS and fMRI. One likely region that receives input from the pSTS, as suggested by nonhuman primate neuroanatomy, is the amygdala (Aggleton et al., 1980; Stefanacci and Amaral, 2000, 2002). A functional connection between the pSTS and the amygdala is proposed in models of face perception (Haxby et al., 2000; Calder and Young, 2005) and is consistent with fMRI data showing that the amygdala responds selectively when viewing different facial expressions (Morris et al., 1996; Whalen et al., 1998). The results of the present study, showing that transient disruption of the right pSTS reduced the BOLD response to faces (but not to bodies or objects) in both the rpSTS and the right amygdala, indicate that the two regions are functionally connected. In addition, TBS delivered over the $\mathrm{rpSTS}$ also reduced the BOLD response to faces in the raSTS, a second face-selective STS region, downstream of the rpSTS, located close to the temporal pole (Pinsk et al., 2009; Pitcher at al., 2011a). These results are consistent with the exis- 

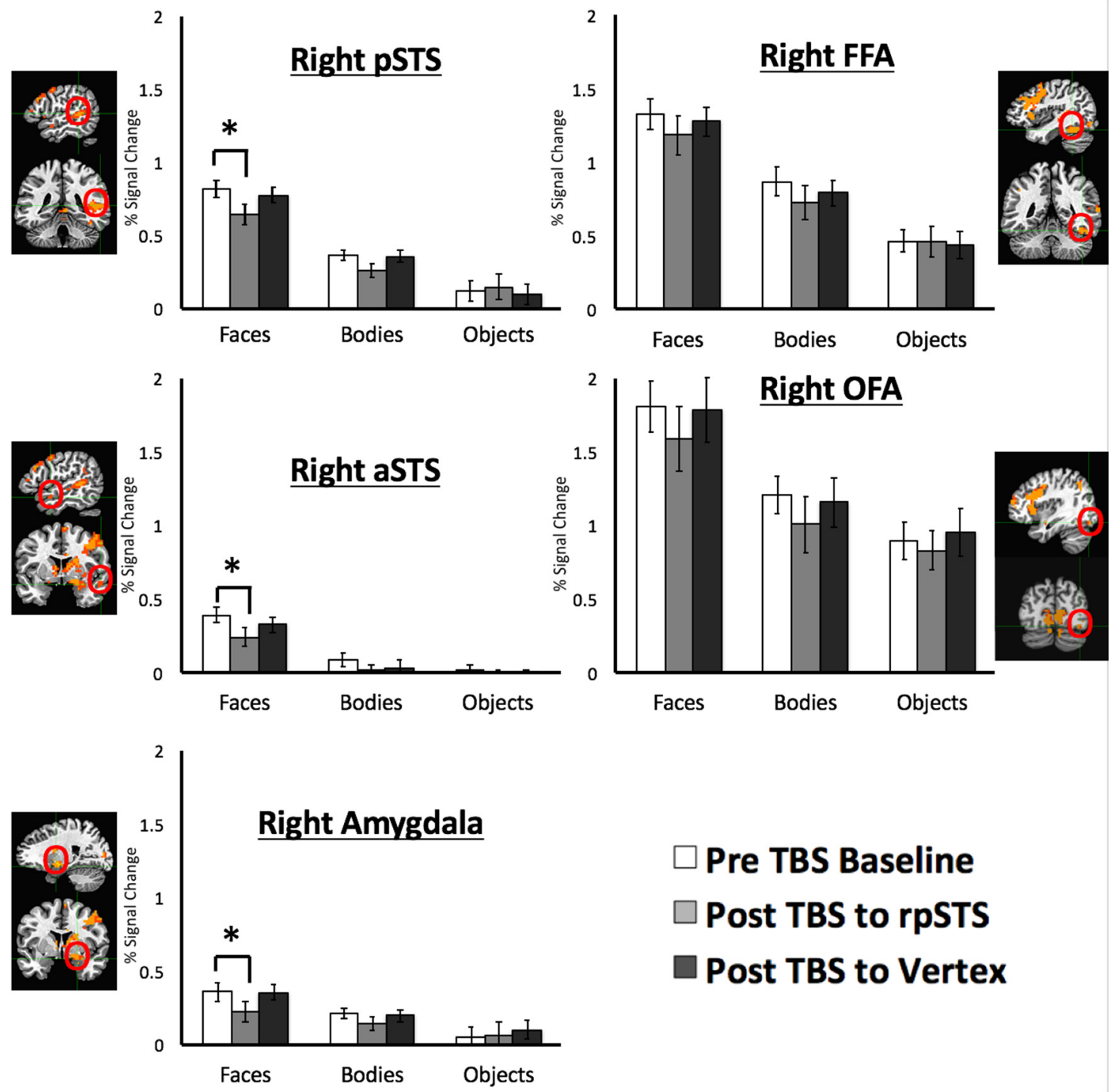

Figure 2. Percentage signal change data for the dynamic face, body, and object stimuli before and after TBS in the five core ROls: the rpSTS, raSTS, right amygdala, rFFA, and rOFA. Error bars indicate standard error. Brain slices show examples of the face-selective (dynamic faces $>$ dynamic objects) ROls in a typical participant. TBS delivered over the rpSTS selectively and significantly reduced the BOLD response to dynamic faces only in the rpSTS, raSTS and right amygdale. *Significant effects.

tence of a cortico-amygdala pathway for processing face information projecting from the rpSTS, via the raSTS, into the amygdala.

The classic models of two visual cortical streams do not account for how changeable facial aspects, such as expression and eye gaze, are processed in the human brain (Ungerleider and Mishkin, 1982; Goodale and Milner, 1992). In humans, neither the dorsal nor ventral pathways include the pSTS (but see Kravitz et al., 2013), suggesting the possibility that it may be part of a putative third pathway. A third pathway, beginning in the motion-selective region MT and projecting down the STS, devoted to motion processing was proposed in a prior macaque neuroanatomical study (Boussaoud et al., 1990). Further anatomical evidence for this third pathway comes from a human tractography study demonstrating that face-selective regions in the STS are only sparsely connected with face-selective regions on the ventral surface of the brain, such as the FFA (Gschwind et al., 2012). The present data further support the existence of this third pathway by showing that TBS delivered over the rpSTS reduced the BOLD response to faces in the downstream face-selective region in the raSTS and in the right amygdala.
Further evidence suggests that the functional inputs to the STS essential for face perception may be, at least in part, independent of the ventral pathway. Neuropsychological studies have shown that patients with lesions of the ventral occipitotemporal cortex still exhibit neural activation to face stimuli in the pSTS (Steeves et al., 2006; Dalrymple et al., 2011; Rezlescu et al., 2012, 2014). More recently, in our prior combined TBS/fMRI study, we demonstrated that the neural response to dynamic face information in the rpSTS was unaffected by TBS disruption of the rOFA, the presumed main input to the face cortical network and part of the ventral pathway (Pitcher et al., 2014). In the present study, TBS delivered over the rPSTS reduced the BOLD response to dynamic faces in the rFFA and rOFA (Fig. 2), but this reduction was not statistically significant. A functional connection between the pSTS and the FFA is predicted in face processing models (Haxby et al., 2000; Calder and Young, 2005), but the evidence for this connection is inconsistent. In the first experiment of our earlier study (Pitcher et al., 2014), TBS delivered over the rpSTS reduced the BOLD response to faces in the rFFA (Pitcher et al., 2014, their Fig. 3), but in the second experiment TBS delivered over the 
rpSTS had no effect on the BOLD response to faces in the rFFA (Pitcher et al., 2014, their Fig. 4). This inconsistency suggests that further work is required to establish whether and how the pSTS and FFA are functionally connected.

Face-selective regions in the STS respond more strongly to dynamic than static faces, whereas ventrally located face-selective regions, like the FFA and OFA, show a weaker, or no, preference for dynamic over static faces (Labar et al., 2003; Fox et al., 2009; Pitcher et al., 2011a). This pattern of enhanced responses to dynamic, compared with static, faces in lateral relative to ventral face-selective regions has also been shown in macaques (Fisher and Freiwald, 2015). These results suggest that dynamic face information is processed via a functionally distinct cortical pathway, at least partially independent of the rOFA and rFFA, which begins in early visual cortex and projects, via motion-sensitive V5/MT, into the pSTS.

Although the face stimuli used in the current study did not explicitly express emotions, they were rated as more emotional than the body and object stimuli. Despite this, we are confident that our experimental effect was face-specific (and not a general emotion effect) because our TBS target region in the rpSTS was defined using a contrast of faces greater than objects and because this region showed almost no response to objects (Fig. 2). However, given that our face stimuli contained more emotional salience than the bodies and objects, we cannot eliminate the possibility that the rpSTS may be conveying emotional information about the face, rather than just face information per se. Although the STS has not previously been implicated in emotion processing, except in the context of faces and bodies (de Gelder et al., 2015), based on the current study, we cannot categorically say whether the TBS effect is face-related or emotion-related, but rather that it is related to faces with emotional content. This issue will have to be addressed in a future study using face videos that differ in emotional content (e.g., happy faces vs neutral faces). If TBS delivered over the rpSTS reduced the BOLD signal in the amygdala only for the emotional faces but not for neutral faces, then one could conclude that the rpSTS conveys information about the expression in the face, and not just face information per se. A parallel experiment with videos of emotional and neutral body expressions will further help uncover whether the causal link between pSTS and amygdala conveys general emotion or category-specific information.

In conclusion, the existing neuropsychological, TBS, and fMRI evidence suggests that face information can reach the pSTS independently of the ventral pathway, further suggesting the existence of a functionally distinct cortical pathway (O'Toole et al., 2002; Pitcher et al., 2014). The current findings provide evidence to support this hypothesis by showing that this face-selective pathway extends into anterior portions of the STS, and then into the amygdala.

\section{References}

Adolphs R, Tranel D, Damasio H, Damasio A (1994) Impaired recognition of emotion in facial expressions following bilateral damage to the human amygdala. Nature 372:669-672. CrossRef Medline

Adolphs R, Tranel D, Hamann S, Young AW, Calder AJ, Phelps EA, Anderson A, Lee GP, Damasio AR (1999) Recognition of facial emotion in nine individuals with bilateral amygdala damage. Neuropsychologia 37:11111117. CrossRef Medline

Aggleton JP, Burton MJ, Passingham RE (1980) Cortical and subcortical afferents to the amygdala of the rhesus monkey (Macaca mulatta). Brain Res 190:347-368. CrossRef Medline

Allison T, Puce A, McCarthy G (2000) Social perception from visual cues: role of the STS region. Trends Cogn Sci 4:267-278. CrossRef Medline

Boussaoud D, Ungerleider LG, Desimone R (1990) Pathways for motion analysis: cortical connections of the medial superior temporal and fundus of the superior temporal visual areas in the macaque. J Comp Neurol 296:462-495. CrossRef Medline

Calder AJ, Young AW (2005) Understanding the recognition of facial identity and facial expression. Nat Rev Neurosci 6:641-651. CrossRef Medline

Calder AJ, Young AW, Rowland R, Perrett DI, Hodges JR, Etcoff NL (1996) Facial emotion recognition after bilateral amygdala damage: differentially severe impairment of fear. Cogn Neuropsychol 13:699-745. CrossRef Medline

Calder AJ, Beaver JD, Winston JS, Dolan RJ, Jenkins R, Eger E, Henson RN (2007) Separate coding of different gaze directions in the superior temporal sulcus and inferior parietal lobule. Curr Biol 17:20-25. CrossRef Medline

Dalrymple KA, Oruç I, Duchaine B, Pancaroglu R, Fox CJ, Iaria G, Handy TC, Barton JJ (2011) The neuroanatomic basis of the right face-selective N170 in acquired prosopagnosia: a combined ERP/fMRI study. Neuropsychologia 49:2553-2563. CrossRef Medline

de Gelder B, de Borst AW, Watson R (2015) The perception of emotion in body expressions. WIREs Cogn Sci 6:149-158. CrossRef Medline

Fisher C, Freiwald WA (2015) Contrasting specializations for facial motion within the macaque face-processing system. Curr Biol 25:261-266. CrossRef Medline

Fox CJ, Iaria G, Barton JJ (2009) Defining the face-processing network: optimization of the functional localizer in fMRI. Hum Brain Mapp 30:16371651. CrossRef Medline

Gauthier I, Tarr MJ, Moylan J, Skudlarski P, Gore JC, Anderson AW (2000) The fusiform "face area" is part of a network that processes faces at the individual level. J Cogn Neurosci 12:495-504. CrossRef Medline

Goodale MA, Milner AD (1992) Separate visual pathways for perception and action. Trends Neurosci 15:20-25. CrossRef Medline

Gschwind M, Pourtois G, Schwartz S, Van De Ville D, Vuilleumier P (2012) White-matter connectivity between face-responsive regions in the human brain. Cereb Cortex 22:1564-1576. CrossRef Medline

Hadj-Bouziane F, Liu N, Bell AH, Gothard KM, Luh WM, Tootell RB, Murray EA, Ungerleider LG (2012) Amygdala lesions disrupt modulation of functional MRI activity evoked by facial expression in the monkey inferior temporal cortex. Proc Natl Acad Sci U S A 109:E3640-E3648. CrossRef Medline

Haxby JV, Hoffman EA, Gobbini MI (2000) The distributed human neural system for face perception. Trends Cogn Sci 4:223-233. CrossRef Medline

Hoffman EA, Haxby JV (2000) Distinct representations of eye gaze and identity in the distributed human neural system for face perception. Nat Neurosci 3:80-84. CrossRef Medline

Hoffman KL, Gothard KM, Schmid MC, Logothetis NK (2007) Facialexpression and gaze-selective responses in the monkey amygdala. Curr Biol 17:766-772. CrossRef Medline

Huang YZ, Edwards MJ, Rounis E, Bhatia KP, Rothwell JC (2005) Theta burst stimulation of the human motor cortex. Neuron 45:201-206. CrossRef Medline

Kanwisher N, McDermott J, Chun MM (1997) The fusiform face area: a module in human extrastriate cortex specialised for face perception. J Neurosci 17:4302-4311. Medline

Kravitz DJ, Saleem KS, Baker CI, Ungerleider LG, Mishkin M (2013) The ventral visual pathway: an expanded neural framework for the processing of object quality. Trends Cogn Sci 17:26-49. CrossRef Medline

LaBar KS, Crupain MJ, Voyvodic JT, McCarthy G (2003) Dynamic perception of facial affect and identity in the human brain. Cereb Cortex 13: 1023-1033. CrossRef Medline

McCarthy G, Puce A, Gore JC, Allison T (1997) Face-specific processing in the human fusiform gyrus. J Cogn Neurosci 9:605-610. CrossRef Medline

Morris JS, Frith CD, Perrett DI, Rowland D, Young AW, Calder AJ, Dolan RJ (1996) A differential neural response in the human amygdala to fearful and happy facial expressions. Nature 383:812-815. CrossRef Medline

O’Toole AJ, Roark DA, Abdi H (2002) Recognition of moving faces: a psychological and neural framework. Trends Cogn Sci 6:261-266. CrossRef Medline

Pinsk MA, Arcaro M, Weiner KS, Kalkus JF, Inati SJ, Gross CG, Kastner S (2009) Neural representations of faces and body parts in macaque and human cortex: a comparative FMRI study. J Neurophysiol 101:25812600. CrossRef Medline

Pitcher D (2014) Discriminating facial expressions takes longer in the pos- 
terior superior temporal sulcus than in the occipital face area. J Neurosci 34:9173-9177. CrossRef

Pitcher D, Dilks DD, Saxe RR, Triantafyllou C, Kanwisher N (2011a) Differential selectivity for dynamic versus static information in face selective cortical regions. Neuroimage 56:2356-2363. CrossRef Medline

Pitcher D, Walsh V, Duchaine B (2011b) The role of the occipital face area in the cortical face perception network. Exp Brain Res 209:481-493. CrossRef Medline

Pitcher D, Goldhaber T, Duchaine B, Walsh V, Kanwisher N (2012) Two critical and functionally distinct stages of face and body perception. J Neurosci 32:15877-15885. CrossRef Medline

Pitcher D, Duchaine B, Walsh V (2014) Combined TMS and fMRI reveals dissociable cortical pathways for dynamic and static face perception. Curr Biol 24:2066-2070. CrossRef Medline

Puce A, Allison T, Bentin S, Gore JC, McCarthy G (1998) Temporal cortex activation in humans viewing eye and mouth movements. J Neurosci 18:2188-2199. Medline

Rezlescu C, Pitcher D, Duchaine B (2012) Acquired prosopagnosia with spared within-class object recognition but impaired recognition of basiclevel objects. Cogn Neuropsychol 29:325-347. CrossRef Medline
Rezlescu C, Barton JJ, Pitcher D, Duchaine B (2014) Normal acquisition of expertise with a novel object class in two cases of acquired prosopagnosia. Proc Natl Acad Sci U S A 111:5123-5128. CrossRef Medline

Steeves JK, Culham JC, Duchaine BC, Pratesi CC, Valyear KF, Schindler I, Humphrey GK, Milner AD, Goodale MA (2006) The fusiform face area is not sufficient for face recognition: evidence from a patient with dense prosopagnosia and no occipital face area. Neuropsychologia 44:594-609. CrossRef Medline

Stefanacci L, Amaral DG (2000) Topographic organization of cortical inputs to the lateral nucleus of the macaque nonkey amygdala: a retrograde tracing study. J Comp Neurol 421:52-79. CrossRef Medline

Stefanacci L, Amaral DG (2002) Some observations on cortical inputs to the macaque monkey amygdala: an anterograde tracing study. J Comp Neurol 451:301-323. CrossRef Medline

Ungerleider LG, Mishkin M (1982) Two cortical visual systems. In: Analysis of visual behavior (Ingle DJ, Goodale MA, Mansfield RJ, eds), pp 549_ 586. Cambridge, MA: Massachusetts Institute of Technology.

Whalen PJ, Rauch SL, Etcoff NL, McInerney SC, Lee MB, Jenike MA (1998) Masked presentations of emotional facial expressions modulate amygdala activity without explicit knowledge. J Neurosci 18:411-418. Medline 